\title{
NURSES IN ACTION AN INTRODUCTION TO ACTION RESEARCH IN NURSING
}

\author{
EC McKibbin and PJ Castle
}

\begin{abstract}
Action Research is one of the new generation of qualitative research methods in the social sciences which has special significance for nurses in South Africa. The collaborative, participative and reflective qualities of Action Research appeal to practitioners, and lend themselves to joint problem solving activities in local contexts. This paper sets out a rationale for Action Research, then describes its features, strengths, and limitations. Ways of overcoming the latter are suggested. The paper concludes that Action Research has potential applications in the field of nursing, not only for the purposes of practical problem solving, but also for improving the personal and professional practice of nurses, and for emancipating nurses from their subordinate position in the hierarchy of health science.
\end{abstract}

\section{INTRODUCTION}

This paper has three main aims: to introduce to nurses the concept of Action Research and to describe the process and uses of Action Research.

\section{WHAT IS ACTION RESEARCH?}

Action Research has been described as a situational, collaborative, participatory, and self-evaluative research strategy, whose ultimate objective is to improve practice by implementing change and evaluating its effects. (Cohen and Manion, 1989). The central proposition of Action Research is that those who are involved in real life problems can seek solutions to them by joining in a cooperative process of planning, action. observation and reflection. The idea behind this is that participants can understand problems better and gain insight into methods of solving them, if they plan and create a change, then reflect on the effects of this change (Cohen and Manion, 1989; Winter, 1987: Sanford, 1981). Thus in addition to helping participants solve problems, Action Research helps them to gain insight into the nature of problems and problem solving processes. Studying problems in this way is a source of knowledge and ideas which help participants make decisions and evaluate the effects of these. The very process of problem-solving (including the activities of analysis, conceptualization, planning. execution and evaluation) is identical to the process of knowledge-making which is the aim of research. It is through problem-posing and problem-solving activities that Action Research links theory and practice, a process which may be described as "ideas-in-action" (Kemmis and McTaggar, 1992:6).

Action Research is a participative and collaborative process: participants, including the researcher, work together to investigate problems and find solutions to them. The situation is not one of an authoritative, powerful and remote researcher who investigates the behaviour of research subjects, but rather one in which all members of a group share the power and responsibility for shaping the research. Group members are volunteers, but share a commitment to investigating and resolving problems, and to abiding by group decisions.

Participating in a creative and recreative process like this develops participants' sense of personal power and self worth, a fundamental principle of adult education (Brookfield, 1985; Freire, 1985; Knowles. 1980). The processes involved in Action Research - investigation, action and reflection - assume a commitment to adults participating actively in the world, deciding what they want to learn and the best way to learn it. For these reasons Action Research may be considered an educational process as well as a research method, and the scope of its application is extraordinarily wide (Davidoff et al, 1993; Brooks and Watkins, 1994; Carr and Kemmis, 1986).

\section{WHEN IS ACTION RESEARCH USED?}

Cohen and Manion (1989) suggest the use of Action Research whenever specific knowledge is required for a specific problem in a specific situation, or when a new approach is to be grafted on to an existing system. Contexts in which Action Research may be used effectively include teaching, leaming, evaluating attitudes and values, in-service training, organizational development, management and administration. Action Research may be used for a number of purposes:
- to spur individuals and groups to action;

- to enhance interpersonal relations, morale and motivation within groups;

- to improve professional functioning and efficiency;

- to promote organizational change;

- to initiate planning, policy-making, implementation and evaluation;

- to introduce innovation and change; and

- to develop knowledge and skill for specific and general situations.

In a later section of this paper, the ways in which Action Research has been used in nursing will be described, and the emancipatory potential of Action Research will be explored.

\section{HOW DOES ACTION RESEARCH DIFFER FROM TRADITIONAL FORMS OF RESEARCH?}

After the second world war, nursing is said to have copied the experimental approaches of medicine in research, in the same way that education borrowed positivist notions from behaviourial psychology (Lacey and Lawton, in Meyer, 1993). The dominant research paradigm of the past two centuries, positivism, is based on the belief that valid knowledge can be established only on the basis of what is founded in 'reality', as perceived by the senses. Positivist claim that science, and only science, offers an adequate base for research because it alone employs methods which ensure that knowledge is not contaminated by subjective preference and personal bias (Carr and Kemmis, 1986; Reason and Rowan, 1981). Scientific research aims to describe, analyze and explain phenomena. so as to predict and control events. Scientists, or researchers, develop theories about the external world, in which it is assumed that facts are readily observable (Torbert, 1981). They then conduct pre-planned experiments, under rigorously controlled conditions, in order to verify their theories. The role of the researcher is detached, in order to minimize disturbance of the phenomena under investigation. It is assumed that the researcher has superior knowledge of the phenomena at the outset of the investigation, and that subjects' contribution to the research will be minimal. 
Thus the researcher exercises external and unilateral control in gaining information from, and acting upon, others.

The past two decades have seen dramatic shifts in the ways that research is understood, valued and used. The trend in the social sciences has been away from empirical research based on positivist paradigms and towards 'post-positivist' or 'new paradigm' research (Reason and Rowan, 1981; Carr and Kemmis, 1986). Reason and Rowan (1981) cite eighteen grounds for disapproval of positivist research, including a narrow model of the person, reductionism, a concern with variables rather than with wholes, an emphasis on testing, low actual utilization of results, a preoccupation with bigness and a tendency to serve conservative interests. But the main objection to positivism lies in its authoritarian nature and its rejection of personal and social values in knowledge creation.

Positivist approaches to research are limited when it comes to dealing with human beings in complex situations. Torbert (1981) remarks that the conditions in which knowledge is gained in scientific research - pre-defined, controlled, uninterrupted - are not the conditions faced by practitioners. He observes:

Practitioners are generally attempting to act well in situations which they do not fully comprehend, in pursuit of purposes which are not fully explicit and to which their commitment is initially ambivalent, and they are being interrupted all the while by other claims on their attention ... what practitioners really require is the kind of knowledge they can apply to their own behaviour in the midst of ongoing events, in order to help them inquire more effectively with others about their common purposes, about how to produce outcomes congruent with such purposes, and about how to respond justly to interruptions. (Torber, 1981: 143)

Rooted in these objections to positivism, alternative approaches to research have emerged in recent years, including phenomenology, ethnography, naturalistic enquiry and symbolic interactionism (Rosenwald and Ochberg, 1992; Carr and Kemmis, 1986). These approaches, which are based on the epistemologies of interpretive social science and critical theory, stress the importance of understanding, meaning and action on the part of individuals and groups. The central proposition of such qualitative approaches to research is that knowledge of our social world is not something hard, real and tangible to be identified, manipulated and validated as in a positivist model; it consists of a complex web of meanings created and sustained by individual members of society. These meanings can only be interpreted by reference to peoples' motives, intentions and purposes. Because knowledge is social, its meaning should be interpreted in social settings and traditions.

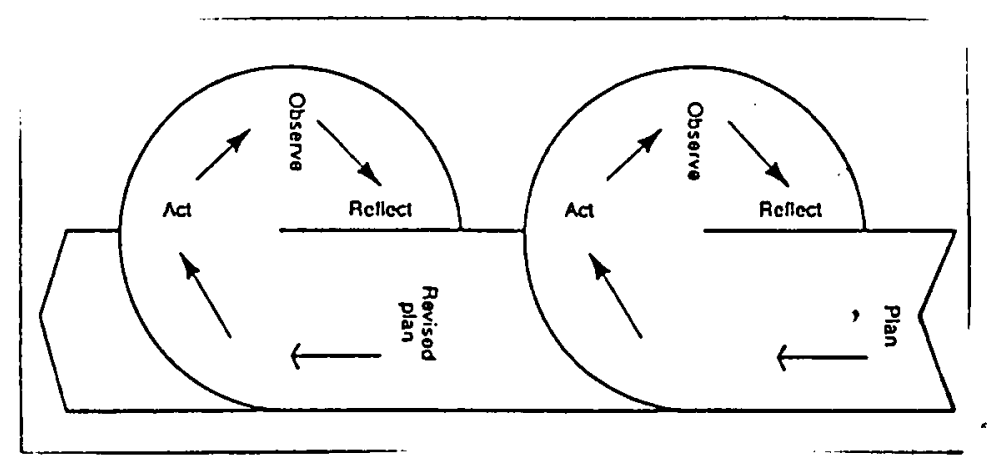

FIGURE 1: THE ACTION RESEARCH SPIRAL

The purpose of qualitative research is to allow researchers to enter into another person's perspective, or to gain new perspectives on their own experience. The qualitative researcher begins with the individual, trying to understand the meaning she ascribes to certain actions or events. A theoretical account (or interpretation) of this action is developed and made available to others, revealing to them the rules and assumptions upon which they have been acting. This account 'enlightens' or 'illuminates' the significance of their actions (Carr and Kemmis, 1986). By offering individuals and groups an opportunity to examine the beliefs and attitudes underlying their actions, they are invited to consider alternative ways of believing and acting, and to create new relationships and practices.

To achieve their aims, qualitative researchers document episodes of human experience representing as closely as possible how people feel, what they know, and what their concerns. beliefs, perceptions and understandings are. Favoured methods include interviews, participant observation and unobtrusive measures, usually conducted in a natural setting with small, non-random samples. Data are usually analyzed inductively, resulting in explanatory themes and concepts. Results are documented in natural language, often in the form of case studies.

\section{WHAT DOES ACTION RESEARCH INVOLVE?}

Action Research involves a four-stage spiral of steps: strategic planning, acting, observing and reflecting.

It is a cyclical, recursive process whereby a plan of action is reformulated on the basis of the information collected, then shared, discussed, recorded and evaluated (Cohen and Manion, 1989). Cunningham (1976) describes the action research process as comprising three stages. The first stage is that of group development, which includes entry into the programme, developing awareness of the need for change, forming the action research group, developing goals for the group, training of group members, and drawing up a contract to secure commitment. The second stage is that of research, and includes defining the problem(s) to be addressed, relating the problem(s) to literature studies, developing tools for data-gathering and analysis, and formulating hypotheses. The third stage is that of action, which includes definition, planning and implementation. During the reflective stage following action, changes and modifications are made to the action plan.

\section{WHAT ARE THE MAIN FEATURES OF ACTION RESEARCH?}

As its name suggests, Action Research aims to integrate research and action. It seeks theories which will inform -but not determine practice. On the one hand, Action Research rejects scientific rigour and precision in favour of practical effectiveness; on the other hand it rejects mere activism by insisting on scrutiny of practical judgements. The reciprocal shaping of theory and practice central to Action Research is captured in the term 'praxis', which emphasizes the theoretically informed and committed nature of action, and the need for theory which is "... open-ended, nondogmatic, informing, and grounded in the circumstances of everyday life" (Lather, 1986: 263). The integration of theory and practice is essential for the twin goals of Action Research, empowerment and change, and has a strong bearing on the process of improving practice.

Action Research is highly regarded as a means of in-service training (Cohen and Manion, 1989) in which practitioners acquire new skills and methods, sharpen their analytic powers. and heighten their awareness of their interventions in the context of everyday life experience. The development of such qualities should lead to improved practice, an important aim in nursing in South Africa. Action Research offers a number of opportunities for improvement of professional practice:

- Participants acquire practical experience of research. They leam to formulate plans for action, examine their practice and reflect critically on the possibilities and constraints of their situation; 
- The research process is demystified as group members become involved in actively directing it rather than passively submitting to it;

- Communications between nurses, researchers, support staff and patients participating in research are facilitated;

- The authority roles which separate researchers and research subjects, nurses and doctors, and nurses and patients are broken down. Participants are engaged as learners, and become committed to a process of self-education;

- It makes good use of the resources in a group; and

- Participants develop problem solving skills, as well as interpersonal and group interaction skills.

As in the field of education, there is currently an emphasis on reflection-in-action in nursing to produce different professional knowledge more appropriate to practice (Meyer, 1993:1067). Action Research, with its opportunities to explore and improve professional practice, seems to offer several advantages in achieving this aim. Schon explains that "thinking-on-your-feet" (1983: 54-5), a process of reflecting on and in action, is the core of practice. As participants begin to make sense of the action, they reflect on the understandings which have been implicit in their action. New understandings surface, are criticized, restructured, and embodied in further action. The process feeds on continuous critical reflection, which may lead to a change in practice or raise new issues and standards for practice (Faulkner and Swann, 1993:246).

Action Research takes place in the complicated climate of an ongoing situation. This makes it highly unlikely that the researcher will know in advance the exact pattern of the enquiry which will develop. The definition of the problem, the questions to be asked and answered, the methods to be employed, are likely to be modified during the course of the research. As findings are validated or invalidated in practice, new questions or solutions are suggested by the developing situation. Participants in Action Research need to investigate their problem and its context carefully, and repeatedly, in order to gain the theoretical insights which will guide and correct their practice. This way of conducting a social enquiry is a mutually educative enterprise.

In order for the Action Research Process to be innovative and developmental, rather than merely repetitive, critical reflection must feature in the process. Critical reflection may be interpreted in at least two ways. It may refer to a self-evaluative process amongst participants (which might be considered 'learning from experience' in a practical context). It may also be considered part of a 'critical theoretical' process (Brookfield, 1985; Freire, 1985) which aims not only to understand, but to change practices by clarifying the values and understandings of those involved in activities, and those who benefit from their continuation. Critical theory urges participants to study the nature and consequences of action; the nature of institutions and structures providing the framework for action; and the nature of the action itself. This 'critical' knowledge is the base for transforming or reconstructing practice, and indeed society as a whole.

\section{WHAT ARE THE LIMITATIONS OF ACTION RESEARCH?}

Action research has been accused of being a form of 'naive enquiry', prone to error (Cohen and Manion, 1989; Lather, 1986). The charge of naivety apparently stems from Action Research's rejection of positivist assumptions about the nature of reality, the authority and control exercised by the researcher, and the appropriateness of experimental methods in uncovering 'the truth'. 'Errors', on the other hand, may stem from the researcher's biases, prejudices and anxieties, or from pressures for group conformity. One implication of this for Action Research is that the design of the research project will have to go beyond the predisposition of group members (or the host organization) to establish a trustworthy basis for problem-solving, decision making and the creation of new ideas.

What validity criteria would serve Action Research best? Lather believes that "we must formulate self-corrective techniques that check the credibility of data and minimize the distorting effect of personal bias upon the logic of evidence" (1986: 270). She suggests a "vigorous self-reflexivity", incorporating concepts of validity taken from traditional research (such as convergent and contextual validity; catalytic validity and internal validity) but in a revised and expanded form. Reason and Rowan (1981) make several practical suggestions for increasing validity in qualitative research, including:

- Involving people with different backgrounds and perspectives in every aspect of the project, increasing the likelihood that the researcher will not always be supported, but also challenged and confronted;

- Using a variety of methods for collecting data (for example interviews, observation, nominal group technique, diary notes, critical incident technique) to get information from a range of primary and secondary sources;

- Employing 'feedback loops', a process of feeding back tentative conclusions to participants for them to mull over and redefine; and

- Developing high quality awareness on the part of co-researchers through systematic methods of personal and interpersonal development.

Several writers (Walker, 1993; Winter, 1987) have questioned the validity of the action-research coupling, noting that practitioners and researchers have distinct objectives and values which are not always compatible. In the struggle for control over the Action Research process (and especially in situations where the Action Research group is under pressure to produce quick, visible results) the action component tends to dominate the research component. When this happens, there is an inclination to elevate commonsense solutions to the status of research findings. Remedies which are already well known are simply put into practice. Action Research then becomes a rationalisation of existing practices with no new insights or concept development. This situation is the converse of the predicament frequently encountered in traditional research studies in which research is carried out but does not lead to action.

One way of preventing the domination of the action component is to insist that the conceptual base of the research 'problem' be explored theoretically, and with reference to previous studies reported in literature, both at the outset of the investigation and at intervals thereafter. This promotes the development of critical, reflective skills amongst participants, while sharing the tasks (and kudos) of research.

An additional but related problem is that the results of Action Research tend to be kept local; they are not shared or communicated with others. This sometimes happens when the research focuses too much on outcomes (solutions to problems) rather than on exploring and reporting the process that leads to them. The scope of the research then becomes 100 local and specific; there is little in it to interest or benefit the wider society.

In Action Research problems are analyzed in a specific context and solutions are sought in that context. The emphasis is on gaining knowledge for a particular situation and purpose rather than on obtaining generalizable scientific knowledge. This specificity has led to charges that Action Research is too local and contextualized, and that it promotes activities of an incidental and 'ad hoc' nature (Cohen and Manion, 1989). However, the process of action research, based on principles of consultation, cooperation and participation, should be relevant to practitioners and researchers more widely, particularly in South Africa with its current climate of rapid and unpredictable social change, dissatisfaction with existing models and services, and emphasis on negotiated solutions to political and other problems at all levels.

The point has already been made that Action Research has the potential to produce mutual learning, new knowledge and solutions to specific problems. Control of the research 
design and process is shared amongst participants, implying that research goals and procedures must be understood and approved by all involved. Critics of Action Research have suggested that such principles are inherently flawed. They maintain that participants' capacity to diagnose problems, implement procedures and evaluate their own actions is often limited. Participants may also lack the authority, prestige or power to secure changes in their situations. Meyer (1993) points out that in the field of nursing, participants, who may be patients and their families, cannot give truly informed consent when the nature of the process is undetermined. The changes proposed in Action Research may be threatening, as may be the nature of the collaborative relationship. Issues such as equality, being in receipt of confidential information (with resultant power and vulnerability), difficulties of maintaining confidentiality and anonymity and so on, may all impact on the capacity of group members to participate fully in problem-solving and strategic planning. In addition, the pressure of external events, and the tolerance of participants, may affect the research process. The existence of such factors needs to be probed at the outset of an Action Research enquiry, and their potential impact acknowledged in the research design.

Finally, Cunningham (1976) and Winter (1987) have observed that the Action Research process has no terminus. The cycles of planning, acting, reflecting and replanning continue as the problems to which they are directed change. Action Research can begin anywhere, and once begun, is without a principle for completion. In this respect, it may be decided to set an artificial limit to activities. It is important to remember, however, that the enquiry may not be finished when the project ends and the report is written.

\section{ACTION RESEARCH AND NURSING}

Titchen and Binnie (1993) suggest that Action Research could be used to further the following interconnected aims in nursing

- To help practitioners research and improve their own practice by generating and testing theory;

- To introduce change and facilitate innovation in professional practice;

- To facilitate professional learning and reflective practice; and

- To democratize health care through the emancipation of nurses from the nursing hierarchy and the traditional role of doctor's handmaiden.

According to Titchen and Binnie (1993) these strategies are interrelated; as nurses research their own practice and innovations, generating and testing theory, they will inevitably leam to think more analytically and critically, thus developing their personal and professional capacities. The bottom-up, collaborative change implied by Action Research has the potential to empower nurses; new work and new roles mean nurses will have to think and act in new ways. Researching and reflecting on their own practice through Action Research can help nurses contribute to health care, thus entering more collegiate relationships with doctors and others. Learning in the personal and professional sphere, linked to changes in perception and in power relationships, leads to organizational and institutional changes. This sounds fine in principle, but what evidence is there to support the promises which Action Research holds out for nursing?

The main aim of nursing is to effect positive change in the health status of people. Meeting this aim requires appropriate action theories, whether or not the practitioner is aware of them. As Yura and Walsh observe,

The nursing process is an orderly, systematic manner of determining the client's problems, making plans to solve them, initiating the plan or assigning others to implement it and evaluating the extent to which the plan was effective in resolving the problems identified.

(In Burgess and Ragland, 1983: 45)

This process sounds remarkably like the Action Research cycle described above. Nurses have followed these steps to address areas of pain, sleeplessness, wound healing and urinary tract infection (Tolley, 1995). They have used Action Research to evaluate painful emergency procedures, orthopaedic procedures and burns (Robinson, 1995). In general nursing care, Action Research has been used to promote more patient-centered nursing, increasing the involvement of patients' families and friends in patient care prior to discharge (Titchen and Binnie, 1993). Action research has also been used to address individual patients' problems from the patient's perspective (McGarvey, 1993; Meyer, 1993).

But nursing cannot be reduced to a physical scientific phenomenon; it is also a social practice, and as such reflects nurses intentions, values and beliefs. According to Hunt (in McGarvey, 1993) nurses do not often engage in original research, nor do they apply findings from others' research. Hunt infers that nurses are often unaware of their potential to contribute to research, or unable to understand, believe, or apply research findings. She acknowledges that they may not be permitted to generate theory or apply research findings. Nelson (1995) suggests that these deficits are systemic rather than personal, due to an absence of a positive research culture in the profession, lack of a managerial framework to support implementation of research findings, and lack of education to enables nurses to understand and apply research.

Action Research may provide a bridge for nurses to change this pattern. Action Research promises to develop participants by promoting their personal and professional development, leading to their emancipation from previously accepted habits, customs and practices (Carr and Kemmis, 1986). Robinson (1995) argues that such revolutions are essential to nursing. It is important for nurses to challenge taken-for-granted practices and promote the development of more collaborative relationships with others. Relationships with others involved in health care (patients, doctors, administrators) can be redefined developed and transformed through Action Research. Collaboration fosters a sense of personal power, and helps participants to feel they own the research process.

Robinson (1995) argues that Action Research can be used to transform nurses' subordinate position in the field of medical practice to one of greater equality. To do this, nurses should move away from positivist assumptions and models of practice upheld by doctors. According to Robinson, the positivist paradigm subordinates "the cherished practice of caring" of nursing (1995: 65) in favour of less productive, less constructive, less thoughtful practices. Nurses' creativity becomes stifled in the pursuit of competencies rigidly performed; critical thinking becomes less important than acting. Robinson charges that nurses' complicity in this subordinate role is enforced not only by the established hierarchy of health workers, but through nurses' own self-monitoring. self-enflagellative, sometimes meaningless practices.

Critical Action Research has the potential to emancipate nurses from their entrenched subordination. As Lather describes it,

... analysing ideas about the causes of powerlessness, recognizing systematic oppressive forces, and acting both individually and collectively to change the conditions of our lives ... Empowerment is a process one undertakes for oneself; it is not something done 'to' or 'for' someone. (1992: 4)

The self-reflection and self-evaluation underpin Action Research process as practitioners learn to look beyond established behaviours and traditions to develop deeper insights into the nature of nursing, and into the structures, processes and politics which control and shape the field. Stark (1994) describes how self-reflection gave her the courage and skills to confront other issues which affected her practice as her self-awareness increased. Stark and Greenwood (1994) claim that the self-evaluative nature of the Action Research process increases flexibility and adaptability, and develops nurses' practical reasoning. analytical and decision-making skills

\section{CONCLUSION}

The last two decades have seen dramatic shifts in the ways in which research is understood, 
used and valued. The trend in the social sciences has been away from positivist research based on a natural scientific model, and towards a 'postpositivist' or 'new paradigm research', characterized by a more qualitative, human and flexible approach to knowledge creation.

This paper has advanced the cause of Action Research in nursing, on the grounds that it is interactive, in the sense that theory and practice interact; contextualized, in the dual physical and social worlds of nursing; and compelling, in the sense that it invites participation in the research process, and in the sense that it helps participants understand and change their worlds.

The writers acknowledge that Action Research is not a flawless or unrivalled route to the creation of knowledge. What Action Research has to offer is a framework for challenging and changing nursing practices, and for understanding the process of doing this. It is the writers' contention that such a framework is appropriate and useful in view of the changing context of nursing in South Africa.

\section{REFERENCES}

Brookfield, S. (1985): A critical definition of adult learning. Adult Education Quarterly, 36 (1): 44-49.

Brooks, A. and Watkins, K.E. (1994): The Emerging Power of Action Inquiry Technologies. New directions for adult and continuing education series, number 63 . San Francisco: Jossey Bass.

Burgess, W. and Ragland, E. (1983): Community Health Nursing: Philosophy, Process and Practice. London: Prentice Hall.

Carr, W. and Kemmis,S. (1986): Becoming critical. Lewes: Falmer Press.

Cohen, L. and Manion, L. (1989): (3rd ed) Research methods in education. London: Routledge.
Cunningham, B. (1976): 'Action research: towards a procedural model'. Human Relations. 29,(3): 239-248.

Davidoff, S., Julie, C., Meerkotter, D. and Robinson, M. (1993) Emancipatory Education and Action Research. Pretoria: Human Sciences Research Council.

Faulkner, D. and Swann, J. (1993): Supporting action research at a distance: the Open University's professional development in action. Educational Action Research. 1,(2): 1993.

Freire, P. (1985): The Politics of Education: Culture, Power and Liberation. South Hadley, Mass: Bergin and Garvey.

Greenwood, J. (1994): Action research: a few details, a caution and something new. Journal of Advanced Nursing. 20: 13-18.

Kemmis, S. and McTaggart, R (Eds) (1992): (3rdEd) The Action Research Planner. Geelong: Deakin University.

Kemmis, S. and McTaggart, R. (1984): The Action Research Planner. Geelong: Deakin University

Knowles, M.S. (1980): The Modern Practice of Adult Education. Chicago: Follett.

Lather, P. (1992): Getting Smarr. New York: Routledge.

Lather, P. (1980): Research as praxis. Harvard Educational Review. 56,(3): 257-277.

McGarvey, H.E. (1993): Participation in the research process: action research in nursing. Professional Nurse. 8,(6): 372-376.

Meyer, J.E. (1993): New paradigm research in practice: the trials and tribulations of action research. Journal of Advanced Nursing. 18: 1066-1072.

Nelson, D. (1995): 'Research into research practice'. Accident and Emergency Nursing. 3,(4): $184-189$

Reason, P. and Rowan. J. (Eds) (1981): Human Inquiry: A Sourcebook of New Paradigm Research. Chichester: John Wiley and Sons.

Robinson, A. (1995): Transformative 'culture shifts' in nursing: participatory action research and the 'project of possibility'. Nursing Inquiry. 2: $65-74$
Rosenwald, G.C. and Ochberg, R.L. (Eds) (1992): Storied Lives: The Cultural Politics of Self Understanding. New Haven: Yale University Press.

Sanford, N. (1981): A model for action research In Reason, P. and Rowan, J. (Eds) Human Inquiry: A sourcebook of New Paradigm Research. Chichester: John Wiley and Sons.

Stark, S. (1994): A nurse tutor's experience of personal and professional growth through action research. Journal of Advanced Nursing. 19: 579-584.

Schon, D.A. (1983): The reflective practitioner. USA: Basic Books.

Titchen, A. and Binnie.A. (1993): A unified action research strategy in nursing. Educational Action Research. 1,(1): 25-34.

Tolley, K.A. (1995): Theory from practice for practice: is this a reality? Jourmal of Advanced Nursing. 21: 184-190.

Torbert, W.R. (1981): Why educational research has been so uneducational: the case for a new model of social science based on collaborative enquiry. In Reason, P. and Rowan, J. Human Ikquiry: A Sourcebook of New Paradigm Research. Chichester: John Wiley and Sons.

Walker, M. (1993): Developing the theory and practice of action research: a South African case. Educational Action Research. 1 (1): 95-109.

Winter, R. (1987): Action research and the nature of social enquiry: professional innovation and educational work. Aldershot: Gower.

Beth McKibbin holds an MSc in community health nursing and has recently completed a Higher Diploma for Educators of Adults. She practices in the field of cardiac counselling and support in Gauteng.

Jane Castle lectures in adult education at the University of the Witwatersrand, and recently completed a PhD at the same institution. She has a keen interest in qualitative research methods and in the professional development of practitioners. 